\title{
ANALYSIS OF SPATIO-TEMPORAL URBAN DYNAMICS IN 11 SMART CITIES OF UTTAR PRADESH, INDIA
}

\author{
Ravi Verma ${ }^{\text {a }}$, P. K. Garg ${ }^{\text {a }}$ \\ ${ }^{\text {a }}$ Department of Civil Engineering, Indian Institute of Technology Roorkee, Roorkee-247667, Uttarakhand, India \\ rverma2@ce.iitr.ac.in
}

KEY WORDS: Smart Cities, Spatio-temporal, Land use change, Landscape Metrics, Shannon's entropy.

\begin{abstract}
:
Urban planning in smart cities needs to be done in a "Smart" way. One way is to analyze the urbanisation pattern by spatio-temporal change detection techniques. Classified data such as, for years 1985, 1995 and 2005 Decadal Land use data for India and for year 2015, Copernicus Global Land service Dynamic Land Cover layers (CGLS-LC100 products) are used to perform multi-temporal analysis of the 11 smart cities of Uttar Pradesh state of India namely "Agra", "Aligarh", "Bareilly", "Jhansi", "Kanpur", "Lucknow", "Moradabad", "Prayagraj", "Rampur", "Saharanpur" and "Varanasi". Dynamics of Urban expansion are studied utilizing concepts of Landscape Metrics calculated by FRAGSTATS and also Shannon's Entropy Values $\left(H_{n}\right)$ over the 11 smart cities. Largest Patch Index (LPI), Landscape Shape Index (LSI), Aggregation Index (AI) and Mean Euclidean Nearest Neighbor Distance (ENN_MN) are metrics used to characterize urbanisation. Results indicate rise in value of LSI over the years from 1985 and with sudden increase in year 2015 for Built-up patches, corroborating more complexity in shapes of Built-up patches in all 11 cities. Kanpur, showing large values of LPI indicates the sudden increase of Built-up land use class over the years. The decreasing value of ENN_MN over the years indicates less centrality for built-up pixels in urbanisation. AI is unchanged for Built-up patches for 1985-1995 but decrease in year 2015 indicates less compactness which is due to dispersion of built-up pixels. High values of $H_{n}$ over the years indicating dispersion of urbanisation in all 11 smart cities except Agra, also validates results.
\end{abstract}

\section{INTRODUCTION}

Urbanisation may be called event, which upon unfolding creates more diversification in land use of city's landscape (Liu et al. 2016). These unchecked forms of urbanisation go on to deteriorate regional climate and health of environment ( $\mathrm{Wu}$ et al. 2016). Characterisation of long-term spatio-temporal urbanisation and understanding of its environmental impacts is a necessary part of urban planning (Li \& Gong, 2016). These impacts can be continuously kept on check by easily available analysis ready data such as Earth Observation (EO) data cubes, and Google Earth Engine (GEE), which has capability of big data analytics in cloud computing environment (Mugiraneza et al. 2020). Combination of modern algorithms or resources help in analysing and checking of extent of urban area in major cities spread around the world (Sapena and Ruiz, 2015). Publically available datasets can be easily used by city planners to mitigate any regional phenomenon destabilizing the local environment (Acosta et al. 2021).

Cities of Asian countries have urban fringes, which may wary more widely at general (Huang et al. 2007) but due to lack of basic infrastructure and rigid state policies, Indian cities have more dispersed and complex growth in recent years (Ramachandra et al. 2019a). In most of the Indian cities, outskirts are lacking rigid policies of development which causes rapid urbanisation at outskirts of cities and subsidiary areas of cities. (Shukla \& Jain, 2019). Over the large change duration of urbanisation, shift in dominance centre is inevitable ( $\mathrm{Li}$ et al. 2013). Urban planning is a tricky matter which needs to be accessed with subjective/perceptual factors to make the city more sustainable (Abastante et al. 2020).

Analysing spatial metrics is first aspect being qualitative and analysing expansion factor being quantitative is the second aspect of urban sprawl analysis (Huang et al. 2007 and Maimaiti et al. 2017). Analysis of landscape scenarios in terms of urban sprawl may bring an effectiveness to its sustainability issue (Yang et al. 2019). A geo-spatial index may prove to be the best indicator for any individual city to show its intrinsic urban sprawl characteristics (Jiang et al. 2007) but at more finer scale such as neighbourhood level with temporal resolution, spatial metrics are distinguished for specifying sprawl characteristics of a city (Ramachandra et al. 2019b). A just investigation into sprawl characteristics of any urban by spatial metrics may prove critical in future planning of any city and boosting its settlement policies (Berling-Wolff and $\mathrm{Wu}, 2004)$.

Shannon's Entropy value have also proven to be an simple and just parameter in many different studies done, to collaborate the population's impact on urbanisation in Indian cities (Bhatta, 2009 and Jat et al. 2008). Irregularity, complexity, compactness (heterogeneity) and centrality are such intrinsic properties depicted by any urban sprawl which may be portrayed by any combination of spatial metrics to analyse urbanisation (Ji et al. 2006, Sun et al. 2013 and Dutta \& Das, 2020). McGarigal and Marks, 1995 introduced such matrices which show us the spatio-temporal change happening in urbanisation of a city. Results of spatial metrics to understand urbanisation taking place spatio-temporally, remain unaffected by resolution of classified images (Wu et al. 2011). 


\section{STUDY AREA}

Cities considered in study area are 11 of the 100 smart cities declared in "SMAERT city Mission" by Government of India in year 2014 for better standard of living of its citizens. Uttar Pradesh being one of the largest state of country got its 11 cities nominated in different phases of mission, to be developed as smart cities. Cities of "Agra", "Aligarh", "Bareilly", "Jhansi", "Kanpur", "Lucknow", "Moradabad", "Prayagraj", "Rampur", "Saharanpur" and "Varanasi" are shown in Figure 1.
Study area is a fragment of fertile Ganga-Yamuna Plane (Doab region). These cities acquire a total of area approximately $5074.27 \mathrm{~km}^{2}$. Cities in itself comprise of rivers, canals passing through centre of it and also reserved forests are situated in it. Rampur is smallest in area $\left(77.44 \mathrm{~km}^{2}\right)$ and capital of Uttar Pradesh state, Lucknow is largest $\left(1232.45 \mathrm{~km}^{2}\right)$. In total these cities acquire $5074.27 \mathrm{~km}^{2}$.

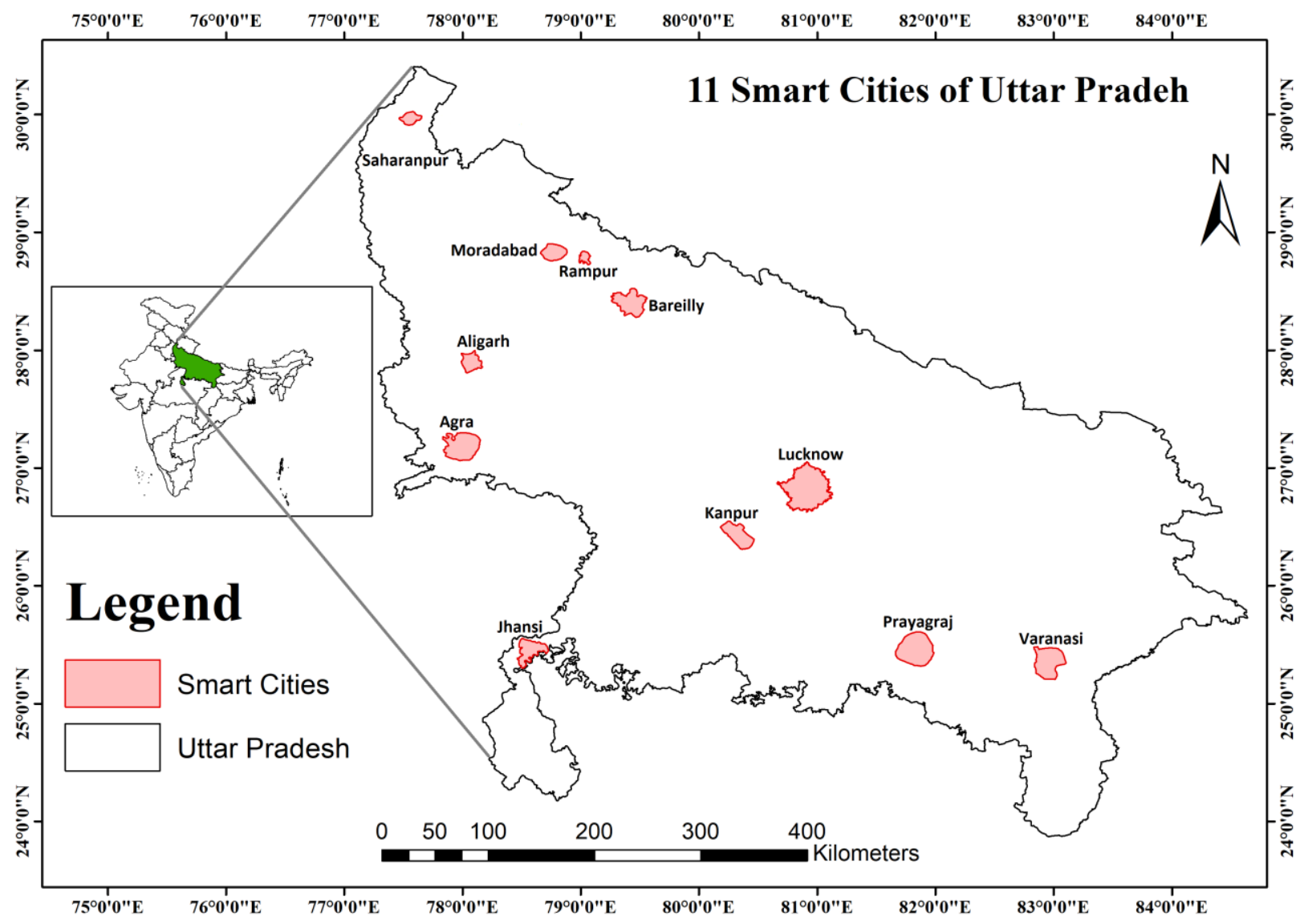

Figure 1. Study area used in study.

\section{METHODOLOGY}

The study has been undertaken to growth of extent of urbanisation in 11 smart cities of Uttar Pradesh.

\subsection{Data used}

For years 1985, 1995 and 2005, Decadal Land use data of India is used as classified maps for study area (Roy et al. 2016) and Copernicus Global Land service Dynamic Land Cover classified map at $100 \mathrm{~m}$ resolution known as CGLS-LC100 product, (Buchhorn et al. 2020) has been used for year 2015.

Google Earth Engine (GEE) platform is used to obtain CGLSLC100 product for year 2015, and ORNL DAAC website is accessed to obtain Decadal Land use data of India for year 1985, 1995 and 2005.

While obtaining Copernicus Global Land service Dynamic Land Cover layer from GEE, re-projection of it is needed and done for ESPG 4326/WGS84 geographic coordinate reference system (CRS) of latitude and longitude.

\subsection{Work flow of study}

All the images of smart cities, are gathered by clipping directly from Decadal ORNL DAAC LULC classified images and CGLS-LC100 product for further analysis. Both of data thus obtained as classified images, are of same $100 \mathrm{~m}$ resolution.

Decadal ORNL DAAC LULC classified images comprise of 17 land use classes and 9 in boundary of India and Uttar Pradesh study area respectively. These 9 classes have been reclassified into 5 analysis ready classes as shown in Table 1.

Likewise, CGLS-LC100 product accessed through GEE for study area, also contain 11 land use classes, which are reclassified into 5 similar classes as in reclassified ORNL DAAC data shown in Table 1 for analysis in the study. 
Table 1. Land use classes reclassified in the study.

\begin{tabular}{|c|c|c|}
\hline $\begin{array}{l}\text { Land use } \\
\text { class used } \\
\text { in study }\end{array}$ & $\begin{array}{l}\text { Land Use classes } \\
\text { merged in Decadal } \\
\text { ORNL DAAC data }\end{array}$ & $\begin{array}{l}\text { Land Use classes } \\
\text { merged in CGLS- } \\
\text { LC100 product }\end{array}$ \\
\hline Built-up & Built-up Land & Built-up \\
\hline Vegetation & $\begin{array}{c}\text { Deciduous } \\
\text { Broadleaf Forest, } \\
\text { Shrub land and } \\
\text { Plantations }\end{array}$ & $\begin{array}{l}\text { Shrubs, Herbaceous } \\
\text { vegetation, Closed } \\
\text { forest, deciduous } \\
\text { broad leaf/ not } \\
\text { matching any of the } \\
\text { other definitions and } \\
\text { Open forest, } \\
\text { deciduous broad leaf/ } \\
\text { not matching any of } \\
\text { the other definitions }\end{array}$ \\
\hline Water & Water Bodies & $\begin{array}{c}\text { Permanent water } \\
\text { bodies }\end{array}$ \\
\hline Agricultural & Cropland & $\begin{array}{c}\text { Cultivated and } \\
\text { managed vegetation / } \\
\text { agriculture }\end{array}$ \\
\hline Other & $\begin{array}{l}\text { Fallow Land, } \\
\text { Wasteland and } \\
\text { Permanent } \\
\text { Wetlands }\end{array}$ & $\begin{array}{c}\text { Bare / sparse } \\
\text { vegetation and } \\
\text { Herbaceous wetland }\end{array}$ \\
\hline
\end{tabular}

Landscape metrics help studying in quantification of spatial grouping of landscape, patches and its classes. Complexity, centrality, compactness and continuity are properties which can entirely describe the landscape of study area.
LPI (Largest patch index) accesses the pattern of landscape in its continuing size over the study area. Complexity of landscape is measured by Landscape shape Index (LSI) as complexity symbolises the irregularity in patch size of land use class.

Centrality is assessed by Mean Euclidean Nearest-Neighbor distance (ENN_MN) metrics. The Mean Euclidean NearestNeighbor distance (ENN_MN) measures the shortest edge to edge distance (Euclidean distance) between a patch from nearest patch of concerned class in its neighborhood. It is the in landscape. Aggregation Index (AI) helps in measuring the compactness of patches of a land use class in landscape. Compactness defines the spatial arrangement of patches of similar properties which largely depends upon patch shape of patches and distance between them. These indices can be calculated using FRAGSTATS (McGarigal \& Marks, 1995) as depicted below (Figure 2).

Classified images of study area from year 1985 to 2015, saved in GeoTIFF file format were used for computation of various Landscape Metrics in batch process in FRAGSTATS and then the values thus obtained were analysed for urban sprawl pattern in study area over change duration of 30 years in 11 smart cities.

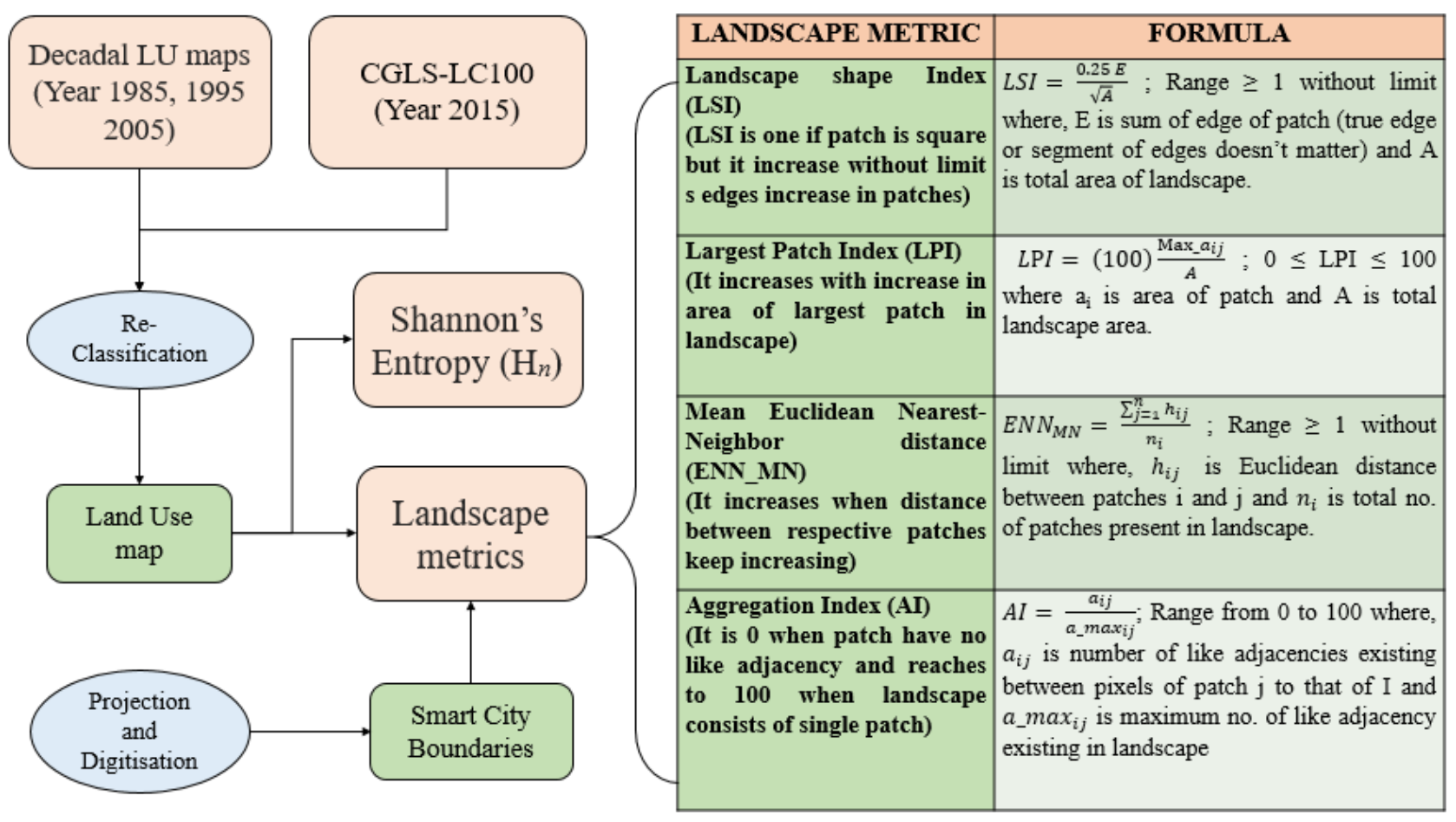

Figure 2. Flow chart showing methodology used in study.

Shannon's Entropy $\left(H_{n}\right)$ is most prominently used index to assess urban growth. It yields the aspect of directional growth of urban area in landscape having ' $n$ ' no. of zones (Ramachandra and Aithal, 2013). Shannon's entropy can be calculated as below by eq. 1 .

$$
H_{n}=-\sum_{i=1}^{n} P_{i} \log P_{i}
$$

Where, $\mathrm{n}$ is the no. of zones in study area, which in this study is 11 (smart cities of Uttar Pradesh) and $\mathrm{P}_{i}$ is the proportion of built-up area in the particular zone, so $\mathrm{P}_{i}$ can be describes as ratio of built-up area to the total area of zone. Shannon's entropy ranges from 0 to $\log _{e}(n)$ and depicts dispersion of builtup area in zone. Higher goes the value of $H_{n}$, or in other terms, closer the $H_{n}$ value is to $\log _{e}(n)$, more is the dispersed urban area in zone, depicting scattered pattern of urban sprawl in zone. 


\section{ANALYSIS OF RESULTS \& DISCUSSION}

\subsection{Land Use Change}

\subsubsection{Land use change Magnitude}

Vegetation class has been affected most in the study area, due to urbanisation and change into agricultural land. $2 / 3^{\text {rd }}$ of original amount of "Vegetation" LU class of year 1985 got converted to "Agricultural" LU class and $16.5 \%$ to "Built-up" LU class up to year 2015. Vegetation suffered massive loss in year $2015(10 \%$ of total study area in year 1985 to $3 \%$ in year 2015) due to dispersed urbanisation taking place in smart cities as it was the time of new housing policies taking place in this part of country.

"Other" LU class was also another LU class which saw massive reduction in area by more than $90 \%$ of its original area of year 1985. This reduction in "Other" LU class caused increase in "Agricultural" LU class which also saw contribution from "Vegetation" LU class (Figure 3).

"Water" LU class has seen negligible change over the years, which is due to presence of perennial rivers like Ganga, Yamuna and its tributaries flowing in this vast plane (Table 2).

Table 2. Change Matrix for Land use classes in 11 smart cities of Uttar Pradesh for 1985 to 2015.

\begin{tabular}{|l|r|r|r|r|r|r|r|}
\hline LU Classes & Built-up & Vegetation & Agricultural & Other & Water & 1985 & Decreased \\
\hline Built-up & 422.32 & 6.54 & 68.92 & 0.68 & 7.59 & 506.04 & 83.72 \\
\hline Vegetation & 80.00 & 64.69 & 326.23 & 6.38 & 14.10 & 491.40 & 426.72 \\
\hline Agricultural & 379.35 & 84.83 & 2895.74 & 10.02 & 35.64 & 3405.58 & 509.84 \\
\hline Other & 189.21 & 12.16 & 290.14 & 5.91 & 22.09 & 519.51 & 513.60 \\
\hline Water & 8.23 & 3.43 & 67.73 & 21.71 & 37.45 & 138.54 & 101.09 \\
\hline 2015 & 1079.10 & 171.65 & 3648.76 & 44.69 & 116.87 & & \\
\hline Increased & 656.79 & 106.96 & 753.02 & 38.78 & 79.42 & & \\
\hline
\end{tabular}

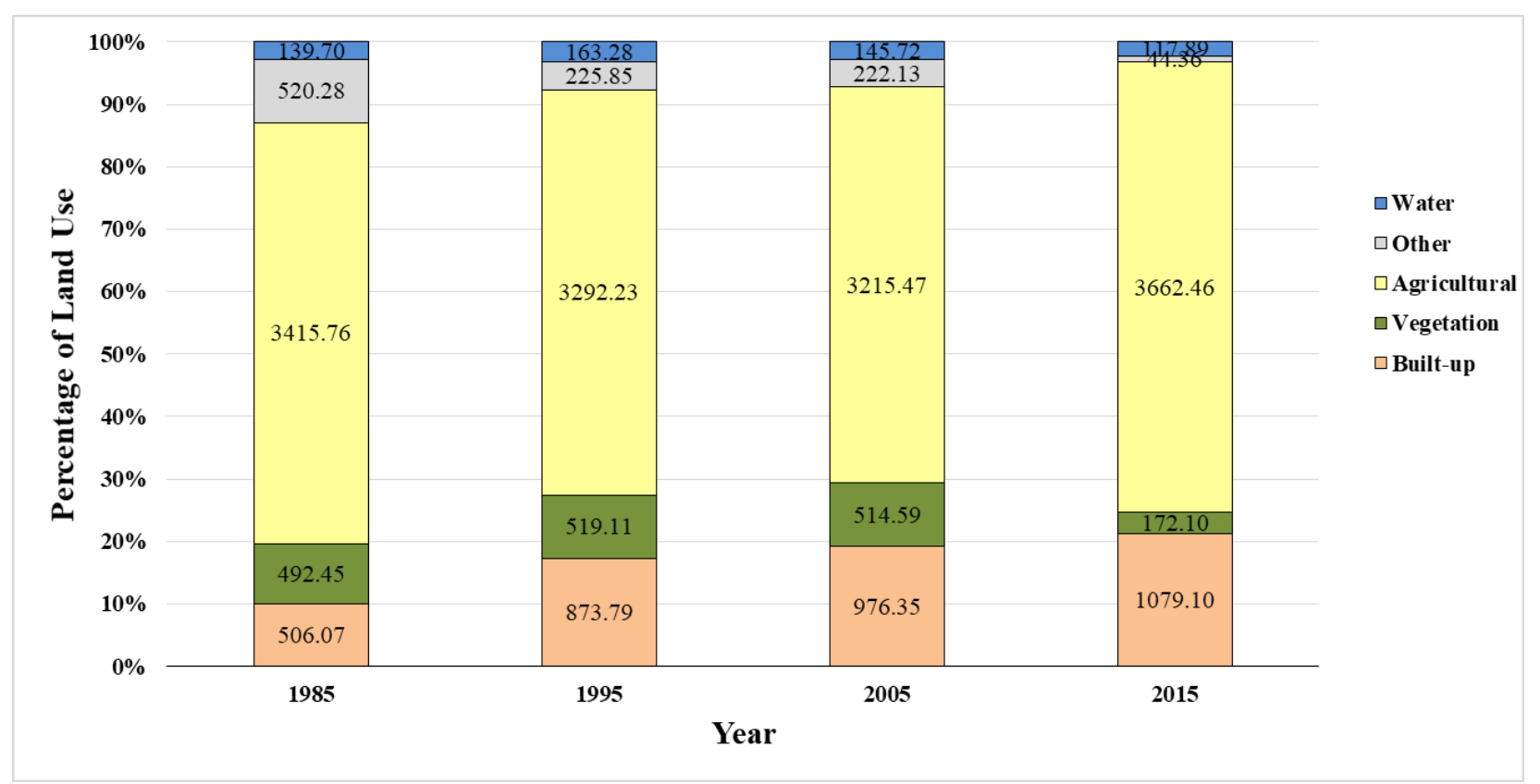

Figure 3. Land use change measured in study area of 11 smart cities of Uttar Pradesh cumulatively

\subsubsection{Land Use change Magnitude}

Smart cities of Uttar Pradesh have changed a lot over the period of 30 years with extensive urbanisation in it. Early change duration of 1985 to 1995 saw a massive increase of 50\% in urbanisation with massive contribution of "Other" LU class in it which contains conversion of barren land to "Built-up" LU class mainly. Later years also witnessed urbanisation but in a much a more different manner of dispersion and more centrality
(Figure 4). In year 1985, in context of Built-up area, Agra was massive contributor with $24 \%$ of whole urban area alone whereas, after 1995 and so on Lucknow and Kanpur have been the first and second most urbanised cities. Bareilly, Prayagraj and Varanasi have seen up in their part in urbanisation but in very little amount by $3 \%$ of total urbanisation in year 2015 whereas, Aligarh, Jhansi and Saharanpur have their part reduced by almost same percentage. 


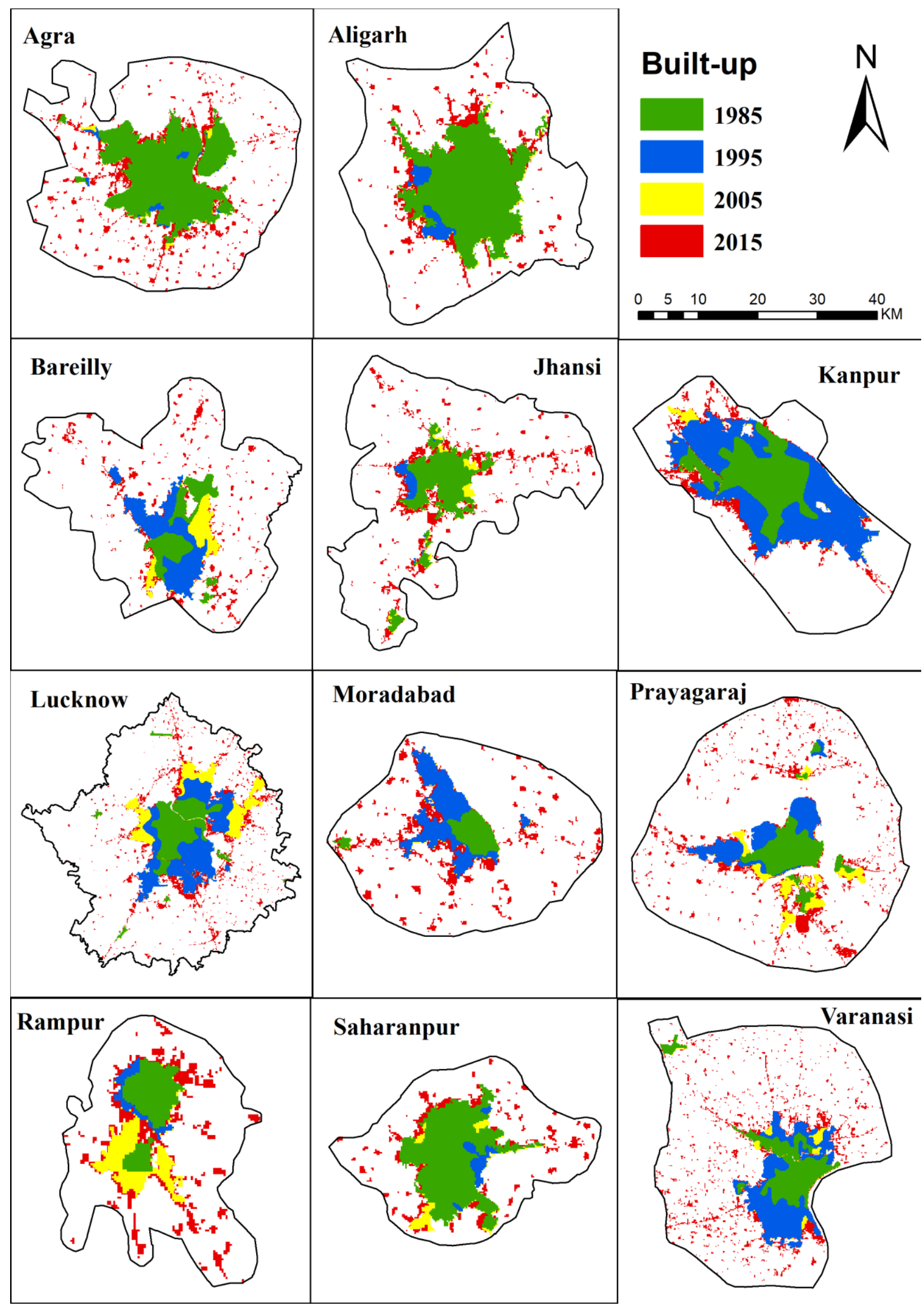

Figure 4. Urbanisation of 11 smart cities over years. 


\subsection{Landscape Metrics}

Landscape metrics (LPI, LSI, ENN_MN and AI) were calculated using equations shown in Figure 2 from FRAGSTATS, for analysing spatial pattern of Built-up patches and characteristics of urbanisation. Figure 5 depicts trend of the metrics LPI, LSI, ENN_MN and AI.

LPI depicting the urbanisation of area and formation of new Built-up patches is highest in Kanpur smart city and it keeps growing from year 1985 to 2015 . Prayagraj is having lowest
LPI over the years, indicating very little urbanisation over the years keeping in line with findings in Figure 4.

All 11 smart cities are exhibiting highest values of LSI in year 2015, indicating the complex shapes of Built-up patches in study area (Figure 5). It may be attributed to formation of new built-up patches in year 2015 in almost all of the 11 smart cities of study area. Higher values of LSI suggest that patches are having more irregularity in their shape, which may be due to generation of less new built-up patches, but more in number.

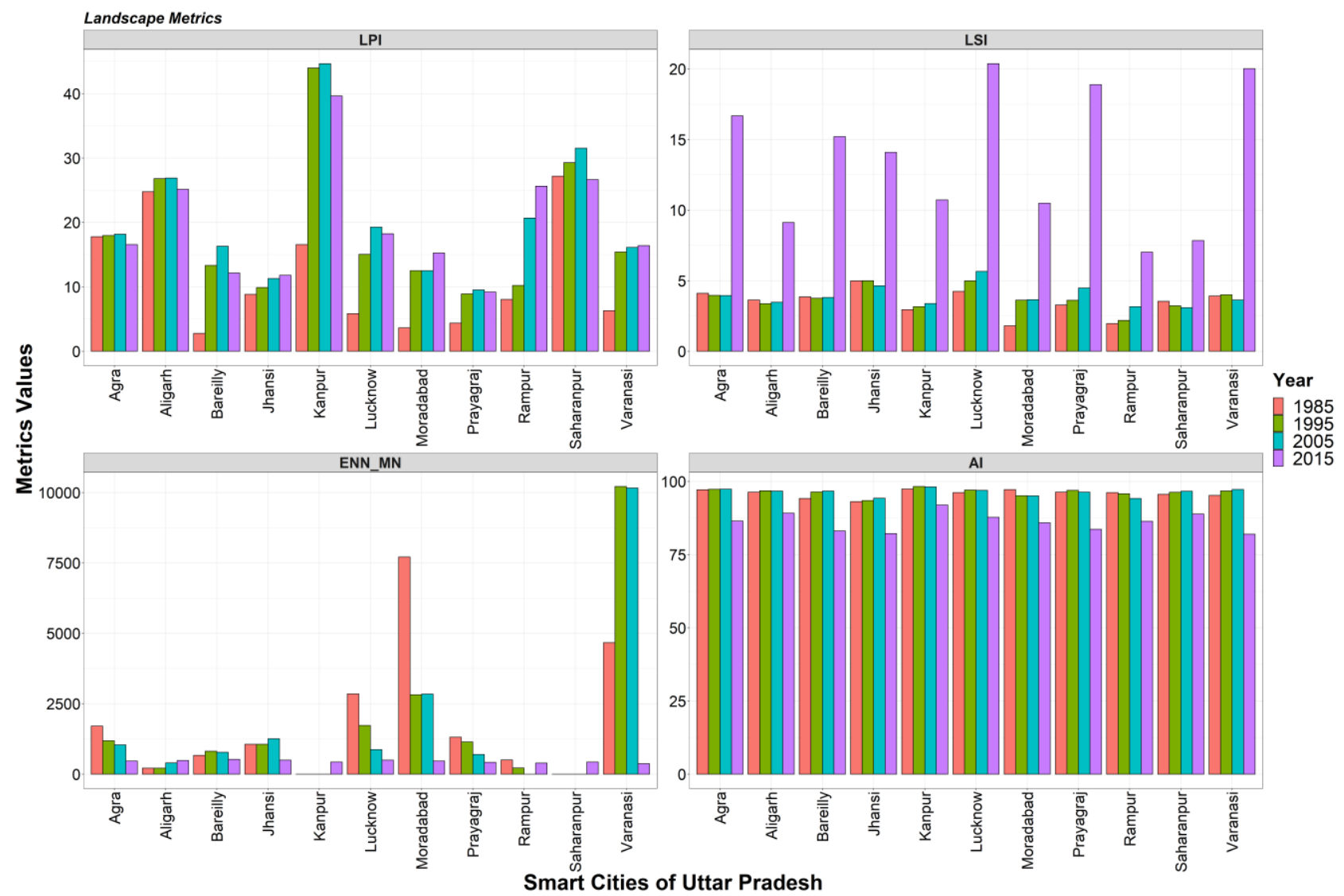

Figure 5. Landscape Metrics for Built-up patches.

ENN_MN in Figure 5 shows that centrality is maximum for Built-up patches of Varanasi from year 1985 to 2005 after which it becomes same as every other smart city in year 2015 . Higher value of ENN_MN suggests that patches are situated at closer to the centre of urban area, which is the reason of lower values of ENN_MN in year 2015 in comparison to year 1985, as urbanisation is continuously expanding in direction apart from centre.

Compactness of urban area is depicted by AI value shown by built-up patches in study area, i.e. bordering of built-up patches by any other land use classes. Each city shows higher values of AI for built-up patches in study area in each year except for year 2015 , meaning that one or many other classes are surrounding built-up patches in all years except in year 2015 thus causing less compactness in year 2015.

\subsection{Shannon's Entropy $\left(H_{n}\right)$}

Shannon's Entropy $\left(H_{n}\right)$ values for 11 smart cities from year 1985 to 2015 are shown in Figure 6 as below. Total no. of cities being 11 in study area $\log _{e}(n)$ is 2.3979 for this study and not even a single entropy value in Figure 6 is even immediate enough to the value of $\log _{e}(n)$ for this study. Although for all the smart cities except Rampur, values of entropy are higher in each year and away from $\log _{e}(n)$, showing more converged pattern of built-up patches in Rampur than other 10 smart cities.

For Lucknow, Kanpur and Prayagraj, entropy values area comparatively higher than other cities and keeps on increasing also over the years showing dispersed urbanisation, but Agra, Aligarh and Saharanpur are showing downward entropy values indicating converged urbanisation over the years. Entropy values keep increasing from year 1985 to 2015 .

It is lowest in year 1985 with entropy value of 2.176 and then it gradually keeps increasing over years 1995 up to 2015 reaching highest of 2.199. These values being close to $\log _{e}(n)$ over the years, tell the dispersing nature of urbanisation in a cumulative way in study area over the change duration. Figure 4 also suggests that urbanisation is accumulated at centre of study area only in starting but kept on dispersing continuously.. 


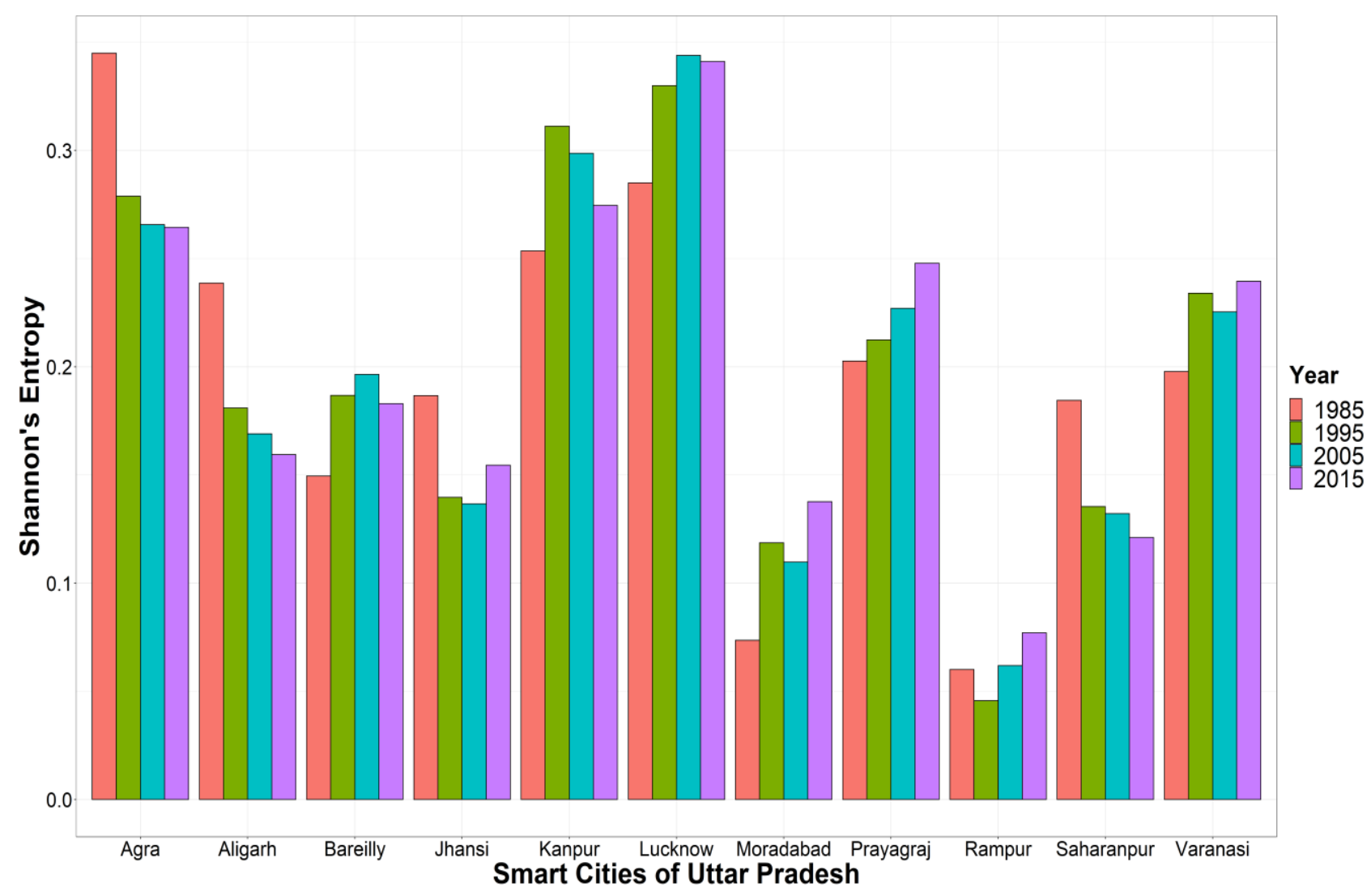

Figure 6. Shannon's Entropy $\left(H_{n}\right)$ value across 11 smart cities of Uttar Pradesh.

\section{CONCLUSIONS}

Spatio-temporal analysis of urban growth pattern of any city helps in recognising the pattern of urbanisation in future but it may become a matter of worry for planners if not done properly for over a vast area of study. This study successfully shows the use of publically available data for analysing relation between urbanisation and its different variables and properties over a change duration of study. Planners can be greatly benefitted using this way of study of urbanisation. Study of directional growth of urban extent in city is helpful in understanding the nature of urban sprawl in specific direction. Investigation in Land use change of study area helps in acknowledging the development policies of administration because trend of change in land use classes follows the path of development only. Urbanisation at boundary of cities is still to occur in foreseeable future.

Landscape metrics are prominent tools in constraining urbanisation and its parameters. Compactness and centrality can govern the allocation of Urban Green Space (UGS) in urban area. Similarly, major part of aesthetics of city from point of city planners can be checked by complexity of built-up patches, which helps in analysing urbanisation pattern of city by mitigating the density part of it for allocation of resources and communication networks in city.

Shannon's Entropy $\left(H_{n}\right)$ value assists in understanding the degree of spatio-temporal change in extent of urban area in a city, in terms of direction and time both. Planners can suggest more area for urbanisation to accommodate more residential area in city, if Shannon's Entropy value is significantly large enough. In presence of smaller value of entropy is in scenario, remaining spaces in cities can be devoted to environment planning such as for cooling effects and aesthetics by issuing the open spaces as Urban Green Space (UGS) such as urban parks,

\section{REFERENCES}

Abastante, F., Lami, I. M., La Riccia, L., \& Gaballo, M. (2020). Supporting Resilient Urban Planning through Walkability Assessment. Sustainability, 12(19), 8131.

Acosta, M. P., Vahdatikhaki, F., Santos, J., Hammad, A., \& Dorée, A. G. (2021). How to bring UHI to the urban planning table? A data-driven modeling approach. Sustainable Cities and Society, 71, 102948.

Berling-Wolff, S., \& Wu, J., 2004a. Modeling urban landscape dynamics: A case study in Phoenix, USA. Urban ecosystems, 7(3), 215-240.

Bhatta, B., 2009. Analysis of urban growth pattern using remote sensing and GIS: a case study of Kolkata, India. International Journal of Remote Sensing, 30(18), 4733-4746.

Buchhorn, M., Smets, B., Bertels, L., De Roo, B., Lesiv, M., Tsendbazar, N.E., Linlin, L., Tarko, A., 2020. Copernicus Global Land Service: Land Cover 100m: Version 3 Globe 2015-2019, Product User Manual; Zenodo, Geneve, Switzerland, September 2020; doi: 10.5281/zenodo.3938963.

Dutta, I., \& Das, A. (2020). Exploring the Spatio-temporal pattern of regional heat island (RHI) in an urban agglomeration of secondary cities in Eastern India. Urban Climate, 34, 100679 . 
Huang, J., Lu, X. X., \& Sellers, J. M. 2007. A global comparative analysis of urban form: Applying spatial metrics and remote sensing. Landscape and urban planning, 82(4), 184-197.

Jat, M. K., Garg, P. K., \& Khare, D., 2008. Modelling of urban growth using spatial analysis techniques: a case study of Ajmer city (India). International Journal of Remote Sensing, 29(2), 543-567.

Ji, W., Ma, J., Twibell, R. W., \& Underhill, K., 2006. Characterizing urban sprawl using multi-stage remote sensing images and landscape metrics. Computers, Environment and Urban Systems, 30(6), 861-879.

Jiang, F., Liu, S., Yuan, H., \& Zhang, Q. 2007. Measuring urban sprawl in Beijing with geo-spatial indices. Journal of Geographical Sciences, 17(4), 469-478.

Li, C., Li, J., \& Wu, J., 2013. Quantifying the speed, growth modes, and landscape pattern changes of urbanization: a hierarchical patch dynamics approach. Landscape ecology, 28(10), 1875-1888.

Li, X., \& Gong, P. (2016). An "exclusion-inclusion" framework for extracting human settlements in rapidly developing regions of China from Landsat images. Remote Sensing of Environment, 186, 286-296.

Liu, Z., He, C. and Wu, J., 2016. General spatiotemporal patterns of urbanization: An examination of 16 world cities. Sustainability, 8(1), p.41.

McGarigal, K., \& Marks, B. J., 1995 FRAGSTATS: spatial pattern analysis program for quantifying landscape structure (Gen. Tech. Rep. PNW-GTR-351. Portland, OR: U.S. Department of Agriculture, Forest Service, Pacific Northwest Research Station, 122 p.) doi:10.2737/PNW-GTR-351

Maimaiti, B., Ding, J., Simayi, Z., \& Kasimu, A., 2017. Characterizing urban expansion of Korla City and its spatialtemporal patterns using remote sensing and GIS methods. Journal of Arid Land, 9(3), 458-470.

Mugiraneza, T., Nascetti, A., \& Ban, Y. (2020). Continuous monitoring of urban land cover change trajectories with landsat time series and landtrendr-google earth engine cloud computing. Remote Sensing, 12(18), 2883.

Ramachandra, T. V., Sellers, J., Bharath, H. A., \& Setturu, B. (2019a). Micro level analyses of environmentally disastrous urbanization in Bangalore. Environmental monitoring and assessment, 191(3), 1-13.

Ramachandra, T. V., Sellers, J., Bharath, H. A., \& Vinay, S. (2019b). Geo-visualization of landscape dynamics in the proposed mega industrial corridor. Environmental monitoring and assessment, 191(3), 1-18.

Roy, P.S., Meiyappan, P., Joshi, P.K., Kale, M.P., Srivastav, V.K., Srivasatava, S.K., Behera, M.D., Roy, A., Sharma, Y., Ramachandran, R.M. and Bhavani, P., Decadal Land Use and Land Cover Classifications across India, 1985, 1995, 2005, 2016. ORNL DAAC, Oak Ridge, Tennessee, USA. doi:10.3390/rs70302401
Sapena, M., \& Ruiz, L. A., 2015. Analysis of Urban Development by Means Of Multi-Temporal Fragmentation Metrics From Lulc Data. International Archives of the Photogrammetry, Remote Sensing \& Spatial Information Sciences, Berlin, Germany, Volume XL-7/W3.

Shukla, A., \& Jain, K. (2019). Modeling urban growth trajectories and spatiotemporal pattern: a case study of Lucknow City, India. Journal of the Indian Society of Remote Sensing, 47(1), 139-152.

Sun, C., Wu, Z. F., Lv, Z. Q., Yao, N., \& Wei, J. B., 2013. Quantifying different types of urban growth and the change dynamic in Guangzhou using multi-temporal remote sensing data. International Journal of Applied Earth Observation and Geoinformation, 21, 409-417.

Wu, J., Jenerette, G. D., Buyantuyev, A., \& Redman, C. L., 2011. Quantifying spatiotemporal patterns of urbanization: The case of the two fastest growing metropolitan regions in the United States. Ecological Complexity, 8(1), 1-8.

Wu, Y., Li, S., \& Yu, S., 2016. Monitoring urban expansion and its effects on land use and land cover changes in Guangzhou city, China. Environmental monitoring and assessment, 188(1), 54.

Yang, J., Li, S., \& Lu, H., 2019. Quantitative influence of landuse changes and urban expansion intensity on landscape pattern in Qingdao, China: Implications for urban sustainability. Sustainability, 11(21), 6174. 